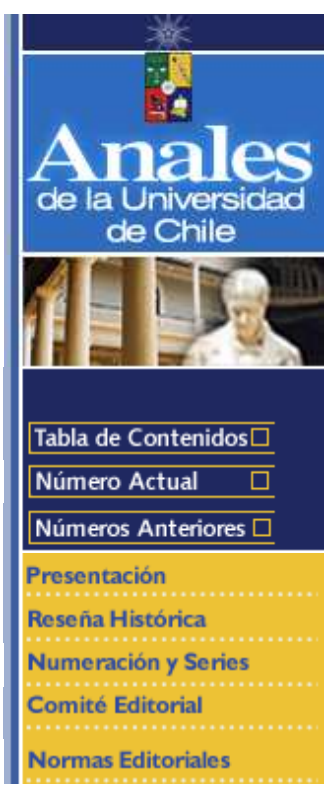

Anales de la Universidad de Chile Sexta Serie, Nº10, diciembre de 1999 


\title{
— Estudios
}

\section{[Neruda el universitario]}

\author{
Figueroa, Juan Agustín
}

Fundación Pablo Neruda

\author{
(日) Cita / Referencia \\ Figueroa, Juan Agustín. Neruda el universitario. Anales de la Universidad de Chile. VI serie: 10, \\ diciembre de 1999. \\ - http://www2.anales.uchile.cl/CDA/an_completa \\ / 0,1281,SCID\%253D127\%2526ISID\%253D8\%2526ACT\%253D0\%2526PRT\%253D97,00.html
}

\section{- Abstract: Neruda the universitarian}

This article begins with a description of Santiago in the 20 s decade, specially in its social, cultural and political environment. Then, it reviews the years when Neruda studied at the Instituto Pedagógico of the University of Chile and stresses the donation of books and shells done by the poet to the University.

\section{: [Texto]}

Neftalí Reyes llegó a Santiago en marzo de 1921, tras día y medio de viaje ferroviario desde su Temuco adoptivo. Este simple hecho nos lleva a dos preguntas cruciales: ¿a dónde llegó?; y ¿qué circunstancias hicieron posible su llegada?

Santiago era una aldea grande, con poco más del $10 \%$ de su actual población. El núcleo propiamente urbano estaba limitado por Avda. Matta, Vicuña Mackenna, Matucana y el río. Pero el ambiente no era apacible. Recién terminaba uno de los años más turbulentos de nuestra historia: 1920. En una reñidísima elección, después de toda clase de alternativas, con intervención de un tribunal de honor, uno de cuyos miembros, en plena sesión, cayó fulminado por un ataque cardíaco, fue elegido Presidente de la República don Arturo Alessandri Palma. Era el triunfo de las capas medias sobre las viejas oligarquías, fundamentalmente de raigambre agraria. Pero aunque las calles atronaban con los alegres acordes del "Cielito Lindo", el proceso había sido largo y doloroso. La efervescencia social se había iniciado ya a fines del siglo anterior, produciéndose situaciones conflictivas entre los trabajadores salitreros y las compañías, que posteriormente tuvieron manifestaciones más o menos violentas en sectores navieros y también en la provincia de Magallanes. Los acontecimientos mundiales, aunque con cierto retardo, también azotaban nuestras costas. La Primera Guerra Mundial, la crisis del salitre, por el invento del salitre sintético, la llegada masiva de la mujer al mundo laboral e intelectual, la revolución bolchevique, la caída de las testas coronadas, el auge del pensamiento socialista, la internacionalización de los movimientos obreros, la actitud aguerrida y combativa de los estudiantes universitarios, conformaban un cuadro complejo, que apuntaba a grandes cambios sociales y políticos.

Esta Casa de Estudio jugó en la dinámica un papel señero. Afianzada en sus estructuras fundamentales, pluralista en su visión de la vida y fuertemente influida por el racionalismo, fue factor determinante de movilidad social. Se fue formando en ella y en su entorno un conjunto de jóvenes talentos que percibían la necesidad de profundas transformaciones en nuestra sociedad. Cristalizan las primeras iniciativas de acercamiento entre estudiantes, intelectuales y trabajadores. En 1910 se crea la "Escuela Nocturna para Obreros" y posteriormente, en 1917, la Universidad Popular José Victorino Lastarria. A ellas se asocian nombres de ilustres catedráticos, como lo fueron Carlos Vicuña Fuentes y Pedro León Loyola.

Muy principal motor de todos estos cambios era la Federación de Estudiantes de nuestra Universidad y su Revista Claridad. En la primera brillaba el talento de los jóvenes que recuerda Neruda en su autobiográfico Confieso que he Vivido: Alfredo Demaría, Daniel Schweitzer, Santiago Labarca, y el señero Juan Gandulfo, a quien el poeta dedica Crepusculario, varios de cuyos poemas se encuentran iluminados con grabados adaptados por él.

La vinculación de Neruda con todo este mundo fascinante, se produce antes de su llegada a Santiago. Como alumno del Liceo de Temuco fue corresponsal de Claridad en esa ciudad. Con orgullo nos cuenta en la recordada autobiografía que entre sus condiscípulos vendía, cada vez, veinte o más ejemplares. Sus colaboraciones en dicha publicación son numerosas y según nos lo asegura Luis Alberto Mansilla en su opúsculo Los Años Verdes de Neruda, ellas llegarían a más de cincuenta, en prosa y en verso. Para las últimas reservaba su ya adoptado seudónimo, y las otras las suscribía como "Sachku" o "Lorenzo Rivas".

Tal relevancia adquirió esta legión estudiantil, recordada como la "Generación del 20", que concitó la malquerencia de los grupos más reaccionarios. Así fue como en las postrimerías de la administración Sanfuentes la Federación de Estudiantes fue asaltada y saqueada. Su mobiliario fue lanzado a la calle y quemado, lo que ocurría ante una fuerza pública impasible. Sus defensores -entre ellos Pedro Gandulfo- fueron procesados acusados de conductas subversivas, y muchos de ellos encarcelados. Entre ellos el fino poeta José Domingo Gómez Rojas. El brutal tratamiento a que fue sometido quebró su frágil arcilla y murió en la cárcel. La Federación fue disuelta por Decreto Supremo y fuertemente reprimido el movimiento estudiantil. 
Pero todo este malestar acumulado, provocado por la torpe represión, se canalizó hacia la candidatura Alessandri, que triunfó prometiendo profundas reformas sociales y políticas.

A esta caldera bullente llegaba el provinciano. A más de los dirigentes estudiantiles que hemos recordado, surgen jóvenes escritores y poetas, también estrechamente vinculados al quehacer universitario. Roberto Meza Fuentes, José Santos González Vera, Manuel Rojas y Alberto Rojas Giménez constituyen, junto con el martitizado Gómez Rojas, un brillante conjunto representativo de ese apasionante momento histórico.

Neruda vino a estudiar pedagogía en francés al viejo Instituto de nuestra Universidad, en Cumming con la Alameda. Pero las turbulencias políticas no son obstáculo, y quizá son estímulo, para desatar la imaginación y la alegría estudiantil. Y aunque nuestro poeta vestía de negro, ya que, al decir de Mansilla, "estaba de luto por el dolor universal", es arrastrado por la algarabía estudiantil y la bohemia. Participa activamente en la Fiesta de la Primavera de 1921. Para gran sorpresa suya, su Canción de Fiesta es elegida como himno ganador en los juegos florales. La revista Claridad la publica en su número 39 de octubre de 1921 y se imprime en una separata con una preciosa litografía del pintor Isaías Cabezón. A los 18 años ve así aparecer su primer volumen y observa, casi con incredulidad, cómo sus cuartetos van siendo cantados y coreados por todo el Santiago bohemio. Es el canto a la alegría y la esperanza juvenil, pero al mismo tiempo ya se asoma en el texto el poeta comprometido con su tiempo y su problemática. Las dos estrofas que ahora transcribo, apuntan en las respectivas direcciones que he señalado. La primera nos dice:

"La juventud con su lámpara clara puede alumbrar los más duros destinos, aunque en la noche crepiten sus llamas su lumbre de oro fecunda el camino"

Y la segunda se desarrolla así:

Y una canción estremece la tierra se alza cantando otra vida mejor en que se miren el hombre y la estrella como se miran el ave y la flor"

Pero el brillante poeta, a quien algunos años después García Lorca visualiza como más cerca de la sangre que de la tinta, no se siente atraído por los cursos regulares del Pedagógico. Abandona estos estudios para dedicarse de lleno a la poesía. Aparece primero Crepusculario y después los Veinte Poemas de Amor y una Canción Desesperada. En el segundo conjunto, entre luces y sombras, entre el lenguaje implícito y las audaces pinceladas, se deslizan -como él después las llama- Marisol y Marisombra, y toma nítido perfil la muchacha de la boina gris. Ellas también eran universitarias y vivían la vorágine de esta dorada década del Veinte.

¿Qué habría sido de Neruda si la Universidad no hubiese sido accesible a las capas medias, de manera de permitir que un modesto ferroviario enviase a su hijo a proseguir estudios superiores en la capital? El talento lo tenía y a raudales, pero quizá, definitivamente afincado en la Frontera, habría sido un poeta notable pero menor, como lo fue Augusto Winter. El Alma Mater, con su realidad polifacética, disonante y contestataria, potenciaron sus inmensos dotes y lo proyectaron al mundo, hasta lograr las magnitudes que hoy conmemoramos.

Neruda explícitamente reconoce su deuda con esta Casa. A comienzos de la década del 50 -treinta años después de haber recibido su bautizo universitario- decide donar a la Universidad su valiosa biblioteca y su completísima colección de conchas marinas. Oigamos sus palabras en el solemne acto que al efecto se desarrolló:

"Yo recogí estos libros de la cultura universal, y estas caracolas de todos los océanos, y esta espuma de los siete mares las entrego a la Universidad por deber de conciencia y para pagar, en parte mínima, lo que he recibido de mi pueblo".

"Esta Universidad no nació por decreto, sino de las luchas de los hombres, y su tradición progresista, renovada hoy por el Rector Gómez Millas, viene de las sacudidas de nuestra historia y es la estrella de nuestra bandera. No se detendrá en su camino. Será algún día la Universidad futura, más ancha y popular, consecuente con las transformaciones profundas que esperamos"

Detengámonos en la maravillosa metáfora que describe a esta Universidad como "la estrella de nuestra bandera". Es la misma que corona nuestro emblema y que flamígera como es, nos ilumina un camino y nos hace avanzar hacia una brillante meta de perfección y de verdad, que afortunadamente jamás se alcanza.

La Universidad y la Fundación hoy se estrechan en un simbólico abrazo y al recordar los 25 años de la muerte de su benefactor, los 45 años de la donación y los casi 80 años de su ingreso a sus aulas, contraen el solemne compromiso de una labor armónica y conjunta, en pro de nuestra poesía y de nuestra cultura.

Abstract: Neruda the universitarian\Resumen | [Texto] | Versión Completa (Imprimir) 